\title{
Sionismo y socialismo en el Centenario de la Independencia peruana
}

Recibido: 16/05/19

Aprobado: 04/08/19

\author{
Patricia Cadenas Erazo \\ Universidad Nacional Mayor de San Marcos \\ Universidad Andina Simón Bolívar (Quito, Ecuador) \\ mpatce@hotmail.com
}

\begin{abstract}
RESUMEN
Se revelan la interinfluencia y la contribución recíproca entre sionismo socialista y socialismo peruano, mediante un esquema explicativo de interacción entre nacionalismo e internacionalismo. Se toma como referente de la realidad histórica las actividades culturales, intelectuales y políticas que, en forma conjunta, llevaron a cabo los judíos socialistas con José Carlos Mariátegui, líder y fundador del socialismo peruano, durante la segunda mitad de la década de 1920, en el marco del Centenario de la Independencia y en razón al ideal común de emancipación social y lucha contra cualquier tipo de opresión que los hermanaba. Se indagará acerca de los elementos comunes en el ideario o pensamiento de las partes referidas, para finalmente establecer el vínculo específico entre los sionistas socialistas y Mariátegui.
\end{abstract}

Palabras clave: Sionismo socialista, socialismo, Centenario de la Independencia, Perú

\section{Zionism and Socialism in the Centennial of Peruvian Independence}

\begin{abstract}
In this work, it is revealed the mutual influence and reciprocal contribution between socialist Zionism and socialism through an explicative outline of the nationalism-internationalism interaction. It implies a historical reference from social reality by means of a description of the cultural, intellectual and political activities that, jointly, the socialist Jews carried out with Jose Carlos Mariategui, the leader and founder of socialism in Peru. They were twinned by their common ideal of social emancipation and struggle against any oppression kind during the second half of the 1920 decade, around the celebrations for the Centennial of Peruvian Independence. For that reason, it is also examined the similarities or shared elements in the ideology and political thought of the concerned parties, to establishing finally the specific link between socialist Zionists and Mariategui.
\end{abstract}

KeYwords: Socialist Zionism, socialism, Centennial of Independence, Peru 


\section{Introducción}

A través de esta investigación, se pretende evidenciar la contribución de los activistas judíos en la formación, desarrollo e identidad del socialismo peruano, durante la segunda mitad de la década de 1920. ${ }^{1}$ Huelga decir que, en el periodo 1925-1930, se registra con mayor intensidad la labor e influencia de los judíos socialistas en el pensamiento y la obra de José Carlos Mariátegui, fundador y líder del Partido Socialista Peruano (PSP), motivo por el cual se precisa conocer: ¿cuál fue la contribución de los activistas judíos al desarrollo del socialismo peruano entre 1925 y 1930 ?

Adoptando una perspectiva predominantemente histórica, dentro de lo que se denomina historia intelectual e historia global, ${ }^{2}$ se propone ver la ma-

1 Los activistas judíos que contribuyeron a perfilar el socialismo peruano entre 1925 y 1930 formaron parte de aquel sector askenazí de judíos que, procedente de Europa Oriental o de Alemania inclusive, inmigró a tierras americanas desde fines del siglo XIX y durante las primeras décadas del siglo xx. La conexión desarrollada entre Mariátegui y los judíoakenazíes durante la segunda mitad de la década de 1920 emergió de dicho contexto y en función de la afinidad socialista, transversal a todos ellos. De esta manera, entre 1925 y 1930, se hizo evidente la configuración de un pensamiento socialista judíomariateguino.

2 No es la intención, en el presente artículo, reflexionar teóricamente sobre el enfoque histórico — confluencia de historia intelectual e historia global o lo que podría fusionarse en una «historia intelectual global» (Moyn y Sartori, 2013)— que enmarca la investigación doctoral de la que surge este artículo. En lugar de ello, lo que aquí se pretende es presentar tan solo un avance de la misma, sin agotar datos ni arribar a proposiciones concluyentes. Sin embargo, una breve aclaración sobre la orientación teórica de la mencionada investigación podría facilitar la comprensión del lector. Lo que puede decirse en forma bastante amplia de la historia intelectual es que esta se ocupa de los intelectuales, las ideas y los patrones intelectuales a lo largo del tiempo (Gordon, 2013: 3er párr.). En otras palabras, su intención es remarcar las propuestas intelectuales junto a la vida y trayectoria de sus propios productores, pensadores o científicos en sí, pero también los contextos socioculturales, sociopolíticos e históricos en los cuales ellas son concebidas. La historia intelectual en suma se ocupa así "del pensamiento en el seno de las experiencias históricas» (Altamirano, 2005a: 10). Consecuentemente, la referida investigación doctoral es un trabajo de historia intelectual dado que, en ella, se aborda el pensamiento de los judíos askenazíes y el de Mariátegui, articulados por el socialismo europeo, cuya expansión mundial entre fines del siglo XIX y las primeras décadas del siglo $\mathrm{xx}$ implica un proceso de difusión que encaja dentro de la perspectiva de la recepción y, a su vez, exige ver las formas de apropiación del socialismo en el continente americano (Tarcus, 2013: 37; 2007). Lo anterior supone, ya, en forma implícita y simultánea, un trabajo de historia global con énfasis en el intercambio y las conexiones (Conrad, 2017: 13-14) por medio del cual se evidencia la migración transatlántica de las ideas socialistas y su circulación en Latinoamérica, tomando como referente la red intelectual que, a nivel continental americano, conformaban Mariátegui, líder fundador del Partido Socialista Peruano (PSP), y los judíos askenazíes, radicados en distintas ciudades ame- nera en la cual el pensamiento judíosocialista, expandido por los inmigrantes askenazíes desde Europa Oriental hacia tierras americanas, contribuyó a dar forma al socialismo en Perú tanto como a difundirlo por Latinoamérica, prestando especial atención a las interacciones e interinfluencias entre las partes implicadas.

Dicha contribución ha sido un aspecto, hasta ahora, soslayado dentro de la historia intelectual y del debate ideológico nacional-peruano (Gonzales, 2014: 11-12), pese a las evidencias sobre la existencia de una red judíomariateguina ${ }^{3}$ de alcance continental en Latinoamérica, conformada especialmente por judíos de actitud liberal, inmigrantes mayoritariamente e hijos de inmigrantes en menor medida, procedentes de Europa Oriental (ej. Rumania, Besarabia) o inclusive de Alemania. ${ }^{4}$

Además del propio Mariátegui, a la cabeza de las editoras Minerva y Amauta, los judíos socialistas que conformaron la red judíomariateguina fueron: los editores de Repertorio Hebreo. Revista mensual ilustrada de cultura (1929) en Lima, Perú, Miguel Adler y Noemí Milstein; el editor de Biblioteca Argentina de Buenas Ediciones Literarias (BABEL), Samuel Glusberg, conocido también con el seudónimo de

ricanas. Esto es establecer la interacción, el intercambio y la interinfluencia de las ideas políticas, socialistas específicamente, que interconectaban Lima (Perú), Buenos Aires (Argentina) y Nueva York (Estados Unidos), dando lugar a interesantes propuestas políticas y de desarrollo, basadas en la complementariedad entre nacionalismo e internacionalismo.

3 En Lima, esta red judíomariateguina se materializó con la labor editorial de Miguel Adler y Noemí Milstein, editores de Repertorio Hebreo (1929). En un sentido más amplio, sus alcances continentales se extendieron hasta Argentina y Estados Unidos, siendo respectivamente sus puntos de contacto en esos lugares Samuel Glusberg en Buenos Aires y Waldo Frank en Nueva York. Este es un aspecto discutido expresamente en "Latinoamérica como el espacio de la memoria socialista judiomariateguina (1925-1930)", ponencia presentada en el Congreso-Homenaje Internacional Aníbal Quijano, descolonialidad del poder hoy. El compromiso de un legado (3, 6, 7 y 8 mayo 2019), el cual no solo sigue siendo desarrollado por la autora en su tesis doctoral, sino que es materia de un artículo en preparación, para lo cual viene revisando con detalle y profusión, desde hace bastante tiempo atrás, el texto de Tarcus (2001), Mariátegui en la Argentina o las politicas culturales de Samuel Glusberg. Buenos Aires: El Cielo por Asalto. En este trabajo se ha agrupado una de las principales fuentes primarias que son materia de análisis en la tesis, a saber, las correspondencias entre Mariátegui, Frank y Glusberg. De la misma manera, Nuestra América: utopia y persistencia de una familia judia (2008) de Claudio Lomnitz, constituye en tono autobiográfico la historia de vida de sus abuelos, Miguel y Noemí, y de la familia Adler-Milstein a la que ellos dieron origen en América Latina.

4 Hacia 1929, las edades de estos judíos fluctuaba entre los 18 y 41 ańos. 
Enrique Espinoza, en Buenos Aires, Argentina y el escritor estadounidense, Waldo Frank en Nueva York, Estados Unidos, con una notable ascendencia sobre Glusberg y Mariátegui.

Estos judíos que, con marcada influencia socialista-europea, mantuvieron contacto en forma asidua con Mariátegui, en razón al ideal común que los hermanaba, ya, sea fuera del Perú (Waldo Frank y Samuel Glusbeg) o residiendo en él (Miguel Adler y Noemí Milstein), se caracterizaron por el transnacionalismo ${ }^{5}$ de sus ideas. Especialmente, los más jóvenes encontraron en Perú el lugar y las conexiones convenientes para conjugarlas, desplegarlas y expandirlas al resto de América Latina, constituyendo Mariátegui el puente o bisagra hacia la consolidación del socialismo judío en el continente americano.

Así, frente a la prevalencia de prejuicios que homogeneizan o encasillan la comprensión de la colectividad judía bien en Perú 6 , Latinoamérica o en el mundo, se pretende dar cuenta de ciertas particularidades, insospechadas probablemente, las cuales evidencian su heterogeneidad y describen tal vez una faceta nueva e inusitada de la misma: la de aquellos judíos seculares y prosionistas que se desempeñaron como activos gestores y seguidores de la red editorial judíomariateguina.

El periodo elegido (1925-1930) es, además, de mucha efervescencia política y social, en medio de la cual el espíritu rebelde y la actitud antiimperialista de los judíos socialistas contrastaban con el gobierno proburgués y pronorteamericano, además de personalista, autocrático y dictatorial, del presidente Augusto B. Leguía (1919-1930) que coincidió con los preparativos y conmemoraciones por el Centenario de la Independencia peruana.

Asimismo, el punto de partida del marco temporal (1925) es significativo por otras dos razones. En primer lugar, el año 1925 marca el viraje del pensamiento de Mariátegui hacia un socialismo más

5 El referido transnacionalismo — que Mariátegui ([1925]1964: 208) caracterizó como internacionalismo o supranacionalismo- es la denominación dada por la autora de este trabajo al socialismo de los judíos askenazíes, establecidos en Lima y otras ciudades americanas como Buenos Aires y Nueva York, partidarios del sionismo. En otras palabras, el transnacionalismo judío deja ver la interconexión e interinfluencia entre nacionalismo e internacionalismo judíos.

6 De acuerdo con Sandberg (1917), la población judía en Lima era aproximadamente de 300 residentes en 1917. Para 1930, de acuerdo con Shatzky (1952: 159), se contaban alrededor de 1000 judíos en Perú (Trahtemberg, 1989: 201). nacionalista (Terán, 1985, cit. en Beigel 2003: 151) $y$, en segundo lugar, en 1925, se registra la, hasta ahora, primera referencia conocida en la producción escrita de Mariátegui sobre aspectos judíos a saber, "Semitismo y antisemitismo» en La escena contemporánea (Mariátegui, [1925]1964). Por otro lado, el punto de cierre (1930) está sellado por la muerte del líder socialista peruano.

De ahí la pertinencia de describir la colaboración estrecha entre los judíos socialistas y Mariátegui, la cual llegó a configurarse en una red judíomariateguina, especialmente, durante la segunda mitad de la década de 1920, dentro del contexto político de plena apertura del gobierno peruano a la penetración estadounidense en América Latina.

\section{Resultados}

\subsection{Las circunstancias históricas}

La década de 1920 no solo es célebre por la conmemoración oficial del Centenario de la Independencia del Perú. Este periodo es uno de los momentos más dinámicos y complejos de lucha por el control social, exacerbado por los sentimientos nacionalistas por un lado y antiimperialistas por otro entre los intelectuales peruanos y latinoamericanos en razón a las intervenciones de la nueva potencia estadounidense en la región latinoamericana y la expansión capitalista (Pita y Marichal, 2012: 23-25).

Durante esta década, caracterizada por la interinfluencia y conexión entre los principales acontecimientos político-ideológicos, económicos y sociales en los contextos local peruano, regional latinoamericano y global de las primeras décadas del siglo $\mathrm{xx},{ }^{7}$ se hicieron visibles las gestiones de intelectuales progresistas de izquierda que concibieron el socialismo peruano y llevaron a cabo intensas gestiones para expandirlo a nivel continental ${ }^{8}$.

Tales gestiones coincidieron con la inmigración judía al continente americano, procedente especial-

\footnotetext{
7 Entre ellos, la Gran Guerra 1914-1919; los procesos revolucionarios de Rusia 1917 y México 1910-1920.

8 Destaca la labor de José Carlos Mariátegui (1894-1930), fundador del Partido socialista peruano (PSP) en 1928.
} 
mente de Europa Oriental (Rumania, URSS ${ }^{9}$ ) y el establecimiento en Perú de judíos askenazíes ${ }^{10}$, vinculados al socialismo europeo y al movimiento obrero judío socialista, debido al antisemitismo y desencanto que el afán monopólico e imperialista de los nacionalismos burgueses europeos ${ }^{11}$ había generado.

De este modo, el ambiente político-ideológico convulsionado en que se produjo la llegada a territorio peruano de los inmigrantes judío-socialistas, junto al desenvolvimiento de sus actividades en él, se caracterizó por la emergencia de nuevos actores o sujetos políticos (por ejemplo, clases medias, movimientos obreros y estudiantiles, élites intelectuales) con posiciones e intereses sectoriales enfrentados y en el cual se debatía la solución a los problemas sobre la nación y la democracia.

En consecuencia, los judíosocialistas se desenvolvieron en forma muy vinculada a las gestiones del líder e intelectual peruano, José Carlos Mariátegui, para lograr la expansión del socialismo por todo el continente, especialmente en América Latina, configurando la oposición antiimperialista y antiyanqui en relación con las fuerzas del sector gobernante, proestadounidense y proburgués, del "Oncenio de Leguía» (1919-1930), encargado de las celebraciones del Centenario de la Independencia.

\subsection{El transnacionalismo de los askenazies socialistas en Perú}

Los activistas judíos vinculados a Mariátegui conformaron aquel sector de judíos askenazíes, inmigrantes, con una visión más secular, laica o humanista, seguidores e influenciados por la tradición europea de izquierda ${ }^{12}$. En el periodo de entreguerras, los que llegaron a Perú, procedentes de Europa Oriental, es-

$9 \quad$ La URSS (Unión de Repúblicas Socialistas Soviéticas) fue un Estado federal de repúblicas socialistas que existió en la denominada zona geográfica de Eurasia entre 1922 y 1991.

10 Los azkenazíes son aquellos judíos procedentes de Europa Central (Alemania, Austria) y, sobre todo, Oriental (Rumania, Polonia, República Checa, Hungría, Rusia, entre otros).

11 Los efectos devastadores de la Gran Guerra (o Primera Guerra Mundial) hicieron que los grupos burgueses europeos fueran percibidos entonces como retrógrados y generadores de destrucción, más que de progreso.

12 Ya sea en forma individual o a través de organizaciones, los judíos han protagonizado la historia del socialismo, del marxismo o incluso del liberalismo occidental, con una fuerte presencia en las luchas sociales por el movimiento obrero, los asentamientos sociales, el racismo, el antifascismo o los derechos de la mujer entre otros. pecialmente, desde Rumania, y se establecieron en Lima configuraron un sector diverso y minoritario pero radical de la colectividad judía, peruana.

De acuerdo con Trahtemberg (1989: 25), el arribo de los primeros askenazíes se produjo a partir de 1912, siendo el contexto de la Gran Guerra (19141919) un detonante para la intensificación de tales inmigraciones. En tales circunstancias, se produjo el contacto entre los judíos askenazíes con José Carlos Mariátegui, siendo significativa la cercanía entre ellos (Gonzales, 2014: 26, 34-35; Flores, 1980: 44).

Los judíos socialistas cercanos a Mariátegui, además de abrigar ideas socialistas, estar inconformes con el orden existente y ser admiradores de la Revolución rusa, buscaban el cambio social (Gonzales, 2014: 27). A nivel ideológico, los askenazíes vinculados al proyecto socialista peruano realizaron esfuerzos por integrar sus ideales nacionalistas e internacionalistas, conjugando la lucha por la identidad nacional del pueblo judío con la lucha por la emancipación social (Quiroga y Massó, 2017; Altamira, 2014a).

Así, los sionistas socialistas en Perú conformaron parte de aquel sector más tradicional del socialismo judío en el cual se integraba el nacionalismo judío (sionismo) con el internacionalismo socialista, dando lugar a lo que, en esta investigación, se denomina transnacionalismo judío, configurado en este caso por el sionismo socialista, oxímoron que denota la interconexión e interinfluencia entre nacionalismo e internacionalismo judíos.

El sionismo (nacionalismo judío) de los judíos socialistas no menoscababa su internacionalismo. Para los askenazíes socialistas, partidarios del sionismo, el establecimiento de un Estado que integrara a todos los judíos en la Diáspora conllevaba una mirada algo más flexible a la del ala sionista conservadora con orientaciones fascistas (Quiroga y Massó, 2017; Altamira, 2014b). Miguel Adler, editor de Repertorio Hebreo así lo expresó: «Sionismo y comunismo no se excluyen» (1929, julio-agosto: 2).

Por tal razón, los askenazíes socialistas en Perú militaban en pro de la expansión del socialismo por todo el continente americano, sobre todo, en Latinoamérica. De ahí que podrían ser considerados partidarios de lo que Tejada describe como americanismo o nacionalismo continental (Tejada, 2004, 1998). La caracterización del transnacionalismo (conjugación entre 
nacionalismo e internacionalismo) judío deja ver esta conexión.

\subsection{La concepción nacionalista de Mariátegui}

Dentro del pensamiento socialista de Mariátegui, los aspectos que lo estrecharon a los socialistas askenazíes estuvieron fundados en su concepción respecto de lo que el socialismo representaba para Latinoamérica - por ende para el Perú- y viceversa. Este punto es importante porque permite conjugar el interés de los judíos cercanos a Mariátegui con el de este en lo concerniente al objetivo unánime de encauzar el socialismo en Latinoamérica.

Pero el sentido del socialismo para Latinoamérica y viceversa está ligado a sus consideraciones sobre la «realidad nacional», vale decir, las realidades local peruana y regional-latinoamericana, articulada a un «nacionalismo revolucionario» y al «uso creativo» del marxismo.

La promesa del nacionalismo peruano para Mariátegui era, en el fondo, la de un nacionalismo socialista, basado en el indigenismo vanguardista (Pakkasvirta, 2005: 190). Esto supuso para Mariátegui, posiblemente, una suerte de fusión o mestizaje para conciliar tradición y modernidad, realismo y utopía, lo indígena y lo europeo.

Nacionalismo peruano y nacionalismo internacional (internacionalismo) fueron los ejes sobre los cuales giró la concepción socialista de Mariátegui de acuerdo con Pakkasvirta (190), los cuales constituyeron la base para su propuesta de integración de la herencia occidental europea con los elementos propios indígenas, nacionales y americanos. Este reconocimiento es fundamental para comprender la afinidad de los judíos socialistas con José Carlos Mariátegui.

\subsection{El vinculo entre los judios socialistas y José Carlos Mariátegui}

El vínculo entre los judíos socialistas y José Carlos Mariátegui está dado específicamente en relación con la posibilidad que ambas partes implicadas veían en el socialismo como proyecto humanista a ser consolidado y difundido en América latina. La identificación de los elementos (ideológicos) afines que facilitaron o canalizaron dicho vínculo previamente realizada en los acápites anteriores permite establecer la analogía siguiente: nacionalismo judío (sionismo) es a nacionalismo peruano (indigenismo vanguardista) como internacionalismo judío es a indoamericanismo.

La analogía anterior identifica y vincula claramente ambos idearios, o representaciones: la del judío socialista y la del indígena americano. Si se los tiene en cuenta, el hecho de establecerla resulta casi instantáneo. Lo que Mariátegui vio en común entre esos dos puntales, el judío socialista y el indígena americano, fue la capacidad de resiliencia sostenida en el tiempo para hacer frente a cualquier opresión o circunstancia de marginalidad (Lomnitz, 2018: 99).

De los judíos, admiró siempre su espíritu abierto a la cultura contemporánea (Flores, 1980: 44) tanto como su cosmopolitismo y, de los indígenas, su capacidad de organización comunitaria para resistir los embates del capitalismo, mediante la conformación de cooperativas económicas, en contraste con el obsoleto sistema latifundista y gamonal (Miller, 1999: 158).

En algún momento, Mariátegui escribió con entusiasmo: «El pueblo judío que yo amo no habla exclusivamente hebreo ni yiddish; es políglota, viajero, supranacional» (1929, abril-mayo: 4), implicando con ello que el internacionalismo suponía la superación del nacionalismo, por lo cual configuraba en realidad una suerte de "supranacionalismo», tal cual su propia expresión:

El internacionalismo no es como se imaginan muchos obtusos de derecha e izquierda la negación del nacionalismo, sino su superación. Es una negación dialéctica, en el sentido que contradice al nacionalismo; pero no en el sentido de que lo condene y descalifique como necesidad histórica de una época (Mariátegui, 1929, abril-mayo: 4)

La adhesión de Mariátegui al pensamiento de los judíos socialistas también la enuncia, él mismo, en los términos siguientes:

He declarado ya mi adhesión a la idea de que si alguna misión actual, moderna, tiene el pueblo judío es la de servir, a través de su actividad ecuménica y cosmopolita al advenimiento de una civilización universal. Repertorio Hebreo aparece como un testimonio de que no puede ser otra, en nuestro tiempo, la obra judía [...] Lo que nos interesa en los judíos no son sus reivindicaciones nacionales que, 
como reivindicaciones burguesas, no harían nunca adhesión más que un mediocre y menudo estado colonial; es su aporte a la construcción de una sociedad internacional, de la cual estén proscritas aquellas supervivencias que tan bien conocen los judíos por ser los que más, acaso, las han sufrido: la opresión de las minorías nacionales, el prejuicio de razas (Mariátegui, 1929, abril-mayo: 3-4).

De ese modo, los esfuerzos de Mariátegui estuvieron encaminados a lograr la adaptación de la idea europea del socialismo, en los ámbitos local-peruano y regional-latinoamericano, tomando como aspecto fundamental la integración y el aporte del sector indígena para que sirviera como instrumento en la labor de superación de la situación de pobreza y desplazamiento en la que tradicionalmente se encontraba postrado dicho sector.

Los que mejor habían instrumentalizado y encarnado el socialismo europeo, desde la visión de Mariátegui, fueron los judíos socialistas. En efecto, dos características particulares son notables en ellos, su espíritu ecuménico y su cosmopolitismo. Mariátegui las consideraba precisamente como las que habían permitido trascender el nacionalismo judío o sionismo en general hacia un humanismo universal. Por ello, denominó «renacimiento judío» al humanismo de los judíos socialistas y lo caracterizó como un fenómeno resultante de la Gran Guerra (1914-1919):

Uno de los fenómenos más interesantes de la postguerra es el del renacimiento judío. Los fautores del sionismo hablan de una resurrección del pueblo de Israel. El pueblo eterno del gran éxodo se siente designado, de nuevo, para un gran rol en la historia. El movimiento sionista no acapara toda la actividad de su espíritu. Muchos judíos miran con desconfianza este movimiento, controlado y dirigido por la política imperialista de Inglaterra. El renacimiento judío es un fenómeno mucho más vasto. El sionismo no constituye sino uno de sus aspectos, una de sus corrientes. (Mariátegui, [1925]1964: 208)

Con ello, se verbalizan las virtudes que el librepensador peruano veía reflejadas en sus colaboradores judíos en Perú y en el continente americano (gran adaptabilidad, diversidad grupal e ideológica, supranacionalismo). Consecuentemente, la afinidad de los askenazíes sionistas-socialistas con las ideas de Mariátegui es la misma que los primeros tienen con el socialismo y las ideas de Marx en relación con la injusticia y la desigualdad social. La consigna era usar el nacionalismo judío para el bienestar general (Gonzales, 2014: 51).

Adicionalmente, los judíos socialistas veían en el socialismo una solución eficaz al problema del antisemitismo que se intensificó en Europa entre los siglos XIx y xx: el cambio social que se proponía a través del socialismo hacia una sociedad más igualitaria implicaba, a su vez, terminar con la intolerancia y el odio hacia ellos (Edelberg, 2011).

\subsection{Articulación de la red judío-mariateguina}

La afinidad ideológica entre los askenazíes socialistas y José Carlos Mariátegui se materializó concretamente en las intensas actividades de gestión cultural que, en forma conjunta, dichas partes realizaron con la producción y circulación literaria, el intercambio de ideas y textos escritos, la traducción y edición de artículos, ensayos, notas y correspondencias en publicaciones tales como Babel, revista de arte y critica $^{13}$ (1921-9), Amauta (1926-1930), Cuadernos literarios de Oriente y Occidente (1927-8), La vida literaria (1928-32), Figuras y aspectos de la vida mundial (1929-30), Repertorio Hebreo (1929), constituyendo así una suerte de red judíomariateguina.

Dicha gestión cultural fue posible debido a la cercanía ideológica, intelectual y amical entre las partes. Los askenazíes socialistas en Perú eran asiduos visitantes de Mariátegui. Este vivió prácticamente rodeado de askenazíes socialistas, afines con el sionismo. Solía recibirlos durante las tertulias que organizaba en su casa. Allí, llegaban artistas y escritores que eran, al mismo tiempo, comerciantes, vendedores, hombres de negocios, autodidactas, yidis-hablantes y trabajadores (Gonzales, 2014: 34).

A partir de tales encuentros, el activismo judío adquiere notoriedad. El proyecto socialista peruano se constituye así en una suerte de semillero de judíos

13 A partir de julio 1923, coincidiendo con la edición nº 13, el título de la revista empezó a aparecer como Babel.Revista de bibliografía. Esta revista salió a la luz en 1921 en Buenos Aires, Argentina y sus ediciones se prolongaron hasta el n ${ }^{\circ} 29$, única edición de 1929. Residiendo en Santiago de Chile, Glusberg reactivó su publicación desde 1933 hasta 1951, llegando a convertirse en una revista de influencia cultural decisiva en Chile. 
jóvenes, socialistas y prosionistas. De este modo, emergieron figuras como la de Miguel Adler y Noemí Milstein, joven pareja rumano-askenazí, dedicada a las artes y a las letras en general (Lomnitz, 2018; Gonzales, 2014: 35), la cual mantuvo una estrecha amistad y colaboración con Mariátegui, recibiendo a su vez apoyo de parte de este, y del grupo Amauta para la edición de los cuatro números de Repertorio Hebreo, publicados entre abril y agosto de 1929.

De este modo, con 25 y 18 ańos respectivamente, fungían, ya, como editores de la mencionada revista, al mismo tiempo que replicaban en Lima la intensa gestión de difusión cultural que, sobre materia judía o relacionada a ella, el editor Samuel Glusberg realizaba en Buenos Aires, Argentina. Repertorio Hebreo surgió así de manos de los jóvenes editores como un «órgano representativo de la nueva creación judía, en lengua castellana.» (Adler, 1929, abril-mayo: 1)

En razón a las gestiones editoriales de Glusberg, a través de BABEL, en Argentina y a su labor propiciadora de cultura en general, incluyendo la judía, la capital porteña no solo se imprimió de un gran sentido cosmopolita sino que se convirtió en un centro latinoamericano de irradiación cultural de primer orden. Debido a ello y en forma paralela a Manuel Gleizer (1889-1966), otro editor judío en Argentina, se le confiere el merecido reconocimiento de gestor cultural y editor moderno.

Asimismo, Glusberg fue el más grande difusor de las obras de Mariátegui en Argentina, a partir de lo cual ellas empezaron a difundirse y a conocerse en dicho país. Cabe señalar que los dos editores mantuvieron su comunicación y amistad siempre a la distancia, vía postal, ya que jamás lo hicieron física o presencialmente. La muerte del intelectual peruano socavó el encuentro.

Mariátegui y Glusberg encarnaron así lo que se ha caracterizado como editores "propiaciadores» (Tarcus, 2001) o «programáticos» (Beigel, 2006). Entre 1927 y 1930, ambos intercambiaban correspondencias al mismo tiempo que compartían proyectos de publicación conjunta, los cuales incluían escritos propios o de otros exponentes, judíos y no judíos (Tarcus, 2001).

Lo que demarcó la cooperación entre ambos fue el interés común que tuvieron en la obra y trayectoria del escritor estadounidense, Waldo Frank, otro integrante de la red judíomariateguina, con ascendencia alemana y vocación hispanista-latinoamericanista ${ }^{14}$ y uno de los mayores representantes del americanismo en el continente (Garbisú, 2018; Hernández, 2012: 2).

Tras su estadía en España en 1924 y en razón tanto a la conexión que ahí desarrolló con Ortega y Gasset como a su intenso deseo de conocer a Miguel de Unamuno, su vocación por América hispana se hizo especialmente manifiesta (Garbisu, 2018: 44). Estando en Madrid, conoció también al mexicano Alfonso Reyes y, a través de este, quiso difundir entre la intelectualidad latinoamericana su anhelo por la unidad entre el Norte y el Sur del continente americano, plasmado en su "Mensaje de Waldo Frank a los escritores mexicanos» (45) y anunciado, ya, en su ensayo Our America (1919) (46).

Justamente es célebre la traducción que, en coordinación conjunta, Glusberg y Mariátegui realizaron del ensayo de Frank por sugerencia de su propio autor (Tarcus, 2001: 123 y 128). La edición latinoamericana de Nuestra América (1929) estuvo lista diez años después de su publicación original en inglés, justamente, para que coincidiera con la visita de Frank a Argentina y Perú entre otros lugares (Chile y Bolivia) que recorriera el escritor norteamericano en los últimos meses de 1929.

Pero el conocimiento de Mariátegui sobre Frank fue mucho más temprano. Ya, en 1925, sus escritos sobre aspectos de la vida cultural, política e internacional (ej. "iberoamericanismo»" ${ }^{15}$ ), las alusiones concretas a la propuesta continental de Frank, el americanismo, revelan la proximidad ideológica del pensador peruano con el intelectual judíoestadounidense (Mariátegui, [1925b]2019; [1925a]2019). De la misma manera, ocurría con su valoración sobre la creación literaria de Frank como ensayista ([1925b]2019) y autor de novelas ([1926]2019).

Se evidencia de ese modo y con total contundencia la judeofilia de Mariátegui (Lomnitz, 2018), tanto a partir de sus relaciones directas y cotidianas con

14 Detalles sobre el vínculo entre Mariátegui, Samuel Glusberg y Waldo Frank podrán leerse en "Latinoamérica como el espacio de la memoria socialista judiomariateguina (1925-1930)", artículo que viene preparando la autora para una pronta publicación que fue materia de disertación en el Congreso-Homenaje Internacional Aníbal Quijano, descolonialidad del poder hoy. El compromiso de un legado (3, 6, 7, y 8 mayo 2019).

15 Uno de los textos sobre americanismo de Mariáetgui, «El iberoamericanismo y panamericansimo", fue publicado en Mundial (Lima 8 de Mayo de 1925). 
inmigrantes judíos askenazíes, o sus descendientes, como en su trabajo editorial y de difusión de ideas. Por un lado, convivía prácticamente con ellos en el jirón Washington en Lima y, por otro, los integraba a su labor de intelectual propiciador-programático, a través de trabajos y proyectos editoriales. Configuró así en Lima, un equipo de trabajo con la pareja AdlerMilstein, para insertarla luego en la red transnacional, americana que había conformado con Glusberg y Frank entre Lima, Buenos Aires y Nueva York. ${ }^{16}$

Por medio de todas estas experiencias, Mariátegui se iba nutriendo de la esencia judíosocialista y formando una concepción propia acerca de la cuestión Palestina no solo a partir de sus propias lecturas sino también de los relatos que, sobre la situación judía en general, recibía de parte de los askenazíes socialistas (Gonzales 2014: 35). Con todo ello, su judeofilia se vislumbraba socialista pero también prosionista tal como se percibe cuando cita a Einstein (Mariátegui, ([1925]1964: 213-4):

Einstein, halla el mérito del sionismo en su poder moral. «El sionismo —escribe- está en camino de crear en Palestina un centro de vida espiritual judía». Y agrega: «Es por esto que yo creo que el sionismo, movimiento de apariencia nacionalista, es en fin de cuentas, benemérito a la humanidad».

Algunas de las motivaciones tempranas de Mariátegui en relación con la cuestión o problema judío lo llevó a escribir sobre el semitismo y el antisemitismo en $\mathrm{La}$ escena contemporánea ([1925]1964), convirtiéndose así en el primer pensador peruano en abordar el problema judío. Este estudio no solo vendría a ser su primer libro publicado, sino también una obra pionera con respecto de lo que se ha trabajado sobre judíos sionistas-socialistas en Perú.

16 La autora prepara dos artículos relacionados con la interrelación entre Mariátegui y los judíos askenazíes así como con la red transnacional que sus actividades editoriales configuraron a nivel continentalamericano. El primero, como se ha mencionado anteriormente en este artículo, constituyó la base de su texto para la ponencia presentada en el Congreso-Homenaje Internacional Aníbal Quijano, descolonialidad del poder hoy. El compromiso de un legado (3, 6, 7, y 8 de mayo 2019), titulado "Latinoamérica como el espacio de la memoria socialista judíomariateguina (1925-1930)». El segundo, en preparación, se focaliza propiamente en destacar la labor de gestión cultural de la red transnacional judíomarateguina.

\section{Discusión}

En este trabajo, se sostiene la vinculación entre nacionalismo e internacionalismo, tratando de superar la visión dicotómica, tradicional que considera una relación de oposición, por lo tanto, de contrarios, con poco o nada en común entre dichos términos. Asimismo, dicha vinculación es planteada aquí por la interrelación que se establece con la convergencia entre sionismo y socialismo en el contexto del Centenario de la Independencia peruana y latinoamericana.

Asumido, el primero (sionismo), como una forma de nacionalismo (nacionalismo judío) y, el segundo (ligado al movimiento obrero internacional), como una forma de internacionalismo, la interrelación entre ambos en el contexto del centenario referido se establece teniendo como soporte conceptual y referente teórico a Anderson (2002) ${ }^{17}$.

El historiador inglés ${ }^{18}$ ha puesto en evidencia la interrelación entre nacionalismo e internacionalismo, mediante diversos ejemplos históricos en el ámbito europeo, distinguiendo entre las distintas formas, tipos o características que han adoptado, desde sus orígenes (siglo XVIII) y a lo largo de su propio desarrollo, dichos conceptos en interacción e interinfluencia mutua.

En el caso específico del centenario de las independencias latinoamericanas, pero sobre todo de la peruana y también de la argentina, la peculiar convergencia entre sionismo y socialismo evidencia la interacción, descrita por Anderson (2002), entre nacionalismo e internacionalismo aun cuando ambas convergencias constituyan para sus detractores un contrasentido.

17 El referido artículo, "Internacionalimo: Un breviario», corresponde a Perry Anderson (2002), el cual fue publicado en New left review, (14): 5-24

18 No debe confundirse al historiador inglés, Perry Anderson (2002), autor cuyo artículo, «Internacionalismo: Un breviario», ha sido usado en este trabajo para fundamentar teóricamente la interacción internacionalismo-nacionalismo, con su hermano Benedict Anderson (1936-2015), politólogo reputado internacionalmente por sus estudios sobre nacionalismo moderno y los imperios multiétnicos quien nunca renunció a su nacionalidad irlandesa, pese al cruce de nacionalidades en su familia (irlandesa por línea paterna e inglesa por la materna), a haber nacido en China y a su ferviente interés de investigación por el caso indonesio, al cual estuvo ligado no solo académica y políticamente sino también de modo sentimental hasta el final de sus días. 
Pese a los argumentos contrarios que sostienen la imposibilidad de una convergencia entre nacionalismo e internacionalismo, el oxímoron sionismo socialista (Quiroga y Massó, 2017; Altamira 2014a), lejos de ser un concepto o un hecho inexistente, tiene su asidero en la realidad social, política peruana y latinoamericana, durante la segunda mitad de la década de 1920, en torno al Centenario de la Independencia. Por el contrario a lo que muchos podrían pensar, el sionismo socialista refiere al transanacionalismo judío, resultante de la interconexión e interinfluencia entre nacionalismo e internacionalismo judíos.

\section{Conclusiones}

El activismo judío en el socialismo peruano se hizo más evidente en la segunda mitad de la década de 1920, contrastando con el gobierno proburgués y pronorteamericano del presidente Augusto B. Leguía (1919-1930) que coincidió con los preparativos y conmemoraciones por el Centenario de la Independencia peruana.

Entre 1925 y 1930, el activismo judío en el socialismo peruano y latinoamericano se manifestó en las interacciones que algunos intelectuales judíos askenazíes, residentes en Lima, Buenos Aires o Nueva York, mantuvieron de modo estrecho y frecuente con el fundador del PSP, José Carlos Mariátegui, ya sea en forma directa y personal o por correspondencia.

La judeofilia de Mariátegui quedó así manifiesta tanto en sus relaciones directas y cotidianas con inmigrantes judíos askenazíes, o sus descendientes, como en su trabajo editorial y de difusión de ideas, configurando así una red socialista, judíomariateguina, transnacional entre Perú, Argentina y Estados Unidos, con alcance continental-americano

Conformaron dicha red transnacional el editor de BABEL, Samuel Glusberg, o Enrique Espinoza; en Buenos Aires, Argentina; el escritor estadounidense, Waldo Frank en Nueva York, Estados Unidos, con una notable influencia sobre Mariátegui y Glusberg; y los editores de Repertorio Hebreo (1929), Miguel Adler y Noemí Milstein, en Lima.

El activismo judío en el socialismo peruano adoptó la forma de una intensa labor de gestión cultural, materializada en la producción y circulación literaria que generaron el intercam- bio de escritos y correspondencias, la traducción y la edición de textos sobre la base del ideario socialista-americanista-judíomariateguino.

A nivel ideológico, la interacción entre los judíos socialistas y José Carlos Mariátegui se tradujo también en el esfuerzo conjunto para la consolidación del proyecto socialista en Perú y su expansión por toda Latinoamérica, bajo el ideal compartido del humanismo universal, manifestado en la conjunción sionismo-indigenismo-supranacionalismo.

De esa manera, la influencia de los sionistas socialistas reforzó la idea del supranacionalismo (internacionalismo) en José Carlos Mariátegui para el desarrollo del socialismo en Perú y su expansión continental. Sin embargo, más que la contribución del sionismo socialista al socialismo peruano, los hallazgos refuerzan una relación interactiva y de interinfluencia entre ambos sectores, a través de la conjunción referida entre sionismo-indigenismo-supranacionalismo-

El transnacionalismo judío alude al internacionalismo judío que Mariátegui caracterizó como supranacionalismo y a su convergencia con el nacionalismo judío tanto como a la del socialismo con el sionismo. En otras palabras, el transnacionalismo judío deja ver la interconexión e interinfluencia entre nacionalismo e internacionalismo judíos.

\section{Referencias bibliográficas}

Adler, Miguel (1929, julio-agosto). «Un estado judío en Palestina», en Repertorio Hebreo. Revista mensual ilustrada de cultura, (3-4): 2.

Adler, Miguel (1929, abril-mayo). «Presentación», en Repertorio Hebreo. Revista mensual ilustrada de cultura (1): $1-3$.

Altamira, Jorge [\#AltamiraResponde] (2014a, agosto 2). ¿Qué opina del sionismo socialista? [Archivo de video]. Recuperado de https://www.youtube.com/ watch?v=29bQb8HipuA

Altamira, Jorge (2014b) [\#AltamiraResponde] (2014a, julio 18). ¿Qué opina el Partido Obrero sobre el sionismo? [Archivo de video]. Recuperado de https:// www.youtube.com/watch?v=yyw9vGgLagE

Altamirano, Carlos (2008). Historia de los intelectuales en América Latina. Buenos Aires: Katz Editores

Altamirano, Carlos (2005). «De la historia política a la historia intelectual: Reactivaciones y renovaciones», 
en Prismas. Revista de historia intelectual, (9): 1-10. http://www.historiapolitica.com/datos/biblioteca/ xixaltamirano.pdf

Altamirano, Carlos (2005a). Para un programa de historia intelectual y otros ensayos. Buenos Aires: Siglo XXI Editores Argentina.

Anderson, Perry (2002, marzo-abril). «Internacionalimo: Un breviario». New left review, (14): 5-24.

Beigel, Fernanda (2006). La epopeya de una generación y una revista. Las redes editoriales de José Carlos Mariátegui en América Latina. Buenos Aires: Biblos.

Beigel, Fernanda (2003). El itinerario y la brújula. El vanguardismo estético-politico de JCM. Buenos Aires: Biblos.

Conrad, Sebastian (2017). Historia global. Una visión para el mundo actual. Barcelona: Editorial Planeta S. A.

Edelberg, Diego (2011). «El Socialismo Judío» en Judios \& judaismo (9 octubre). http://www.judiosyjudaismo. com/2011/10/el-socialismo-judio/. Consulta 27 de julio 2016.

Flores, Alberto (1980). La agonía de Mariátegui. La polémica con la Komitern. Lima: Desco Centro de estudios y promoción del desarrollo.

Garbisu, Margarita (2018). "José Ortega y Gasset - Waldo Frank. Epistolario (1922-1930)». Revista de Estudios Orteguinos (37): 37-51.

GonZales, Osmar (2014). La presencia judía en la izquierda peruana. Lima: Otra Mirada, 162 pp.

Gordon, Peter (2013). "What is Intellectual History? A Frankly Partisan Introduction to a Frequently Misunderstood Field». https://scholar.harvard.edu/ files/pgordon/files/what_is_intell_history_pgordon_ mar2012.pdf

Hernández, Sebastián (2013). «Americanismo y judaísmo en Argentina a través de babel y cuadernos de Oriente y Occidente (1921-1929)». En Osvaldo Fernández, Patricio Gutiérrez Donoso y Braulio Rojas C. (Ed). Amauta y Babel, revistas de disidencia cultural (vol. 2, 121-146), Valparaíso: Facultad de Humanidades, Universidad de Valparaíso.

Hernández, Sebastián (2012). «Samuel Glusberg/Enrique Espinoza: revistas culturales y proyectos editoriales en Argentina (1921-1935)». En Universum 2(27):211-221

Lomnitz-Adler, C. (2018). Nuestra América. Ciudad de México: FCE - Fondo de Cultura Económica.

Mariátegui, José Carlos (1929, abril-mayo). "Israel y Occidente, Israel y el Mundo» en Repertorio Hebreo, $\mathrm{n}^{\circ} 1$, Lima.
Mariátegui, José Carlos ([1926]2019). «Rahab», de Waldo Frank. Signos y obras. Obras completas de José Carlos Mariátegui. Recuperado el 9 de julio de 2019 de https://www.marxists.org/espanol/mariateg/oc/ signos_y_obras/paginas/rahab.htm. (Trabajo original publicado en 1926).

Mariátegui, José Carlos ([1925]1964). La escena contemporánea, Lima: Empresa editora Amauta. http://archivochile.com/Ideas_Autores/mariategui_jc/s/Tomo1. pdf. Consulta 29julio2016. (Trabajo originalmente publicado en 1925).

Mariátegui, José Carlos ([1925a]2019). «El iberoamericanismo y panamericanismo". En Temas de nuestra América. Obras completas de José Carlos Mariátegui. Recuperado el 10 de diciembre 2019 de https://www. marxists.org/espanol/mariateg/oc/temas_de_nuestra_ america/paginas/ibero.htm. (Trabajo originalmente publicado en mayo de 1925).

Mariátegui, José Carlos ([1925b]2019). «Waldo Frank». El alma matinal. Obras completas de José Carlos Mariátegui. Recuperado el 11 de junio de 2019 de https://www. marxists.org/espanol/mariateg/oc/el_alma_matinal/ paginas/waldo frank.htM. (Trabajo originalmente publicado en mayo de 1925).

Miller, Nicola (1999). In the shadow of the State. Intellectuals and the quest for National Identity in Twentieht-century Spanish America. New York: Verso.

Moyn, Samuel; Sartori, Andrew, eds. (June 2013). Global Intellectual History. Columbia University Press. ISBN 9780231534598.

PAKKASVIRTA, Jussi (2005). ¿Un continente, una nación?: intelectuales latinoamericanos, comunidad politica y las revistas culturales en Costa Rica y el Perú (1919-1930). San José, C. R.: Editorial Universidad de Costa Rica.

PAlti, Elías (2007). «La nueva historia intelectual y sus repercusiones en América Latina» ["The new intellectual history and its repercussion in Latin America»]. História Unisinos 11(3); 297-305.

Pita, Alexandra y Carlos Marichal (coordinadores) (2012). Pensar el antiimperilaismo. Ensayos de historia inetlectual latinoamericana, 1900-1930. El Colegio de México-Universidad de Colima, México D. F.

Quiroga, M., \& Massó, M. (2017, setiembre). La cuestión nacional judía en el socialismo de Europa del Este: disputas partidarias e internacionales (18921914). Izquierdas, (35), 124-166. doi: 10.4067/ s0718-50492017000400124 
SANDberg, Harry O. (1917). «The Jews of Latin America including South and Central America, Mexico, the West Indies, and the United States Possessions», en The American Jewish year book 5678: 35-232, The Jewish Publication Society of America, Filadelfia.

Shatzky, Jacob (1952). Comunidades judías en Latinoamérica. Buenos Aires: American Jewish Committee.

Tarcus, Horacio (2013). «El marxismo en América Latina y la problemática de la recepción transnacional de las ideas». Temas de Nuestra América. Revista de Estudios Latinoamericanos, 29(54), 35-86. Recuperado a partir de https://www.revistas.una.ac.cr/index.php/tdna/ article/view/6342

TARCus, Horacio (2007). «La historia intelectual y la problemática de la recepción». En Marx en la Argentina. Sus primeros lectores obreros, intelectuales y cientificos (18711910), Buenos Aires: Siglo XXI: 1-55. Recuperado de https://shial.colmex.mx/textos/Tarcus-6.pdf
Tarcus, Horacio (2001). Mariátegui en la Argentina o las politicas culturales de Samuel Glusberg. Buenos Aires: El Cielo por Asalto.

Tejada, Luis (2004). «El americanismo. Consideraciones sobre el nacionalismo continental latinoamericano" en Investigaciones sociales año VIII $\mathrm{N}^{\circ}$ 12: 167-200, UNMSM / IIHS, Lima.

TejadA, Luis (1998). El socialismo indoamericano. La ideología politica de la generación del 20. [Tesis de Doctorado en Sociología no publicada]. École des Hautes Études de Sciences Sociales, París.

Trahtemberg, León (1989). Los judios de Lima y las provincias del Perú. Lima: León Trahtemberg Siederer.

Trahtemberg, León (1988). Demografía Judía del Perú, Lima: Unión Mundial ORT.

Trahtemberg, León (1987). La inmigración judía al Perú 1848-1948. Lima: León Trahtemberg Siederer. 